\title{
The Existence of Random Walk in the Philippine Stock Market: Evidence from Unit Root and Variance-Ratio Tests
}

\author{
Abraham C. CAMBA Jr. ${ }^{1}$, Aileen L. CAMBA ${ }^{2}$ \\ Received: July 03, 2020 Revised: August 23, 2020 Accepted: September 10, 2020
}

\begin{abstract}
The efficient market hypothesis explains the random walk hypothesis suggesting that stock prices are independent of each other, hence, it is impossible to earn abnormal profits. The positive effect of a well-functioning and highly efficient stock market on the performance of an economy motivated the Philippine Stock Exchange to pursue massive modernization initiatives. This research provides evidence of the existence of random walk in the Philippine stock market employing the Augmented Dickey-Fuller (1981) and Phillips-Perron (1988) unit root tests, the Lo-MacKinlay's (1988) conventional variance ratio test, and Chow-Denning's (1993) simple multiple variance ratio test. Results of the ADF and PP unit root tests confirm the necessary condition for a random walk. The Chow-Denning (1993) maximum $\mid z /$ statistic and the Wald test statistic as in Richardson and Smith (1991) for the joint hypotheses and the Lo and MacKinlay (1988) individual statistics variance ratio test generally accepted the null hypothesis of a random walk. That is, the unit root and variance ratio tests consistently indicate that the null hypothesis of random walk cannot be rejected. The existence of a random walk in weak-form efficiency can be attributed to market liquidity as a result of continuous development and modernization of the Philippine equity market.
\end{abstract}

Keywords: Chow-Denning Maximum Statistics, Random Walk, Unit Root, Variance Ratio Test, Wald Test Statistic

JEL Classification Code: C32, G10, G12, G14

\section{Introduction}

The stock market serves as a channel for economic growth (Camba \& Camba, 2020). The most efficient allocation of capital is achieved with development of financial markets and letting the market allocate the capital. The development of stock markets, for instance, is necessary to efficiently allocate resources in an economic system by channeling savings into valuable investments. If a stock market is

${ }^{1}$ First Author and Corresponding Author. Assistant Professor II, Department of Economics, College of Social Sciences and Development, Polytechnic University of the Philippines, Manila, Philippines [Postal Address: P. Tuazon Ave., Bgry. Kaunlaran, Quezon City, Metro Manila, 1111, Philippines]

Email: accamba@pup.edu.ph

${ }^{2}$ Associate Professor IV, Department of Economics, College of Social Sciences and Development, Polytechnic University of the Philippines, Manila, Philippines. Email: alcamba@pup.edu.ph_

(c) Copyright: The Author(s)

This is an Open Access article distributed under the terms of the Creative Commons Attribution Non-Commercial License (https://creativecommons.org/licenses/by-nc/4.0/) which permits unrestricted non-commercial use, distribution, and reproduction in any medium, provided the original work is properly cited. efficient and traders have full information of all listed companies as reflected by the corresponding share prices, then the investment will be allocated to the most efficient opportunity and trading activities for both domestic and foreign investors can take place without much risk (Lean, Mishra, \& Smyth, 2015).

The efficient market hypothesis seeks to explain the random walk theory by positing that only new information will move stock prices significantly, and since new information is presently unknown and occurs at random, future movements in stock prices are also unknown and, thus, move randomly. Simply, random walk theory suggests that stock price changes are independent of one another, therefore the past movement of a stock price cannot be employed to forecast its future movement (Lean \& Smyth, 2007; Rehman, Kashif, Chhapra, \& Rehan, 2018). Hence, it is not possible to earn abnormal profits.

The belief that a well-functioning and highly efficient stock market positively affects the performance of an economy motivated the extensive modernization initiatives of Philippine Stock Exchange that started in 2005 when it adopted the Online Disclosure System (Rufino, 2013). This paper adds to the existing literature in understanding 
the stock market efficiency (i.e., the weak form efficiency). Thus, providing evidence of the existence of random walk in the Philippine stock market is the object of this study.

\section{Theoretical Foundation}

The random walk hypothesis, championed by Louis Bachelier (1900), states that stock prices are random, like the steps taken by a drunk, and therefore are unpredictable. The random walk is explained by the efficient market hypothesis. The efficient market hypothesis states that financial markets are efficient and that prices already reflect all known information concerning stock prices. There are three forms of the efficient market hypothesis that differ in what information is considered (Dupernex, 2007; Mehmood, Mehmood, \& Mujtaba, 2012). Firstly, weak-form efficiency, where past market trading information, such as stock prices, trading volume, and short interest are considered. Secondly, semi-strong form efficiency, which extends the information to public information other than market data, such as news, accounting reports, company management, patents, products of the company, and analysts' recommendations. Thirdly, strong form efficiency which extends the information further to include not only public information, but also private information, typically held by corporate insiders, such as officers and executives of the corporation.

The random walk hypothesis provides a mean to test the weak-form efficiency, hence, non-predictability of financial markets (Charles \& Darné, 2009; Brealey, Myers, \& Allen, 2005; Cuthbertson \& Nitzsche, 2004). Given a time series $\left\{S P R I C E_{t}\right\}_{t=1}^{T}$, the random walk hypothesis corresponds to $\varphi=1$ in the first-order autoregressive model:

$$
\operatorname{SPRICE}_{t}=\mu+\varphi S P R I C E_{t-1}+\varepsilon_{t}
$$

where SPRICE are stock market price, $\mu$ is an unknown drift parameter and the error terms $\varepsilon_{t}$ are, in general, neither independent nor identically distributed (i.i.d.).

\section{Literature Review}

\subsection{Using as Basis of the Unit Root Tests}

The following studies confirm the random walk existence and a weak form market efficiency after applying different unit root statistical techniques. Worthington and Higgs (2006) investigate the market efficiency in weak-form in Asian-pacific stock markets. Daily returns of five developed markets (Hong-Kong, Japan, New-Zealand, Australia, and Singapore) and ten emerging (China, Indonesia, India, Korea, Malaysia, Philippines, Pakistan, Sri-Lanka, Thailand and Taiwan) were observed for random walks. The unit root tests concluded that all markets are weak-form efficient except the markets of Australia and Taiwan. Lean and Smyth (2007) apply univariate and panel Lagrange Multiplier (LM) unit root tests with one and two structural breaks to examine the random walk hypothesis for stock prices in eight Asian countries. The results from the univariate LM unit root tests and panel LM unit root test with one structural break suggest that stock prices in each country is characterized by a random walk, but the findings from the panel LM unit root test with two structural breaks suggest that stock prices in the eight countries are mean reverting. Mehmood et al. (2012) describe the movement of share prices of companies listed at Karachi Stock Exchange (KSE) from January 2, 2001 to November 15, 2011 with 2672 observations. Simple unit root - Augmented Dickey-Fuller (ADF) and Phillips-Perron (PP) tests - and Johansen Co-integration test findings suggest that KSE-100 Index follows the Random Walk Hypothesis (RWH) and Efficient Market Hypothesis (EMH). Thus, KSE is an efficient financial market that can adjust to any new information efficiently and share prices of listed companies cannot be predicted. Hence, KSE cannot be beaten to gain any abnormal return.

There are also studies that do not follow the random walk hypothesis. Hamid, Suleman, Shah, and Akash (2010) conducted a study to check the random walk behavior and weak form efficiency in Asia-pacific region, which includes stock markets of Australia, China, Hong-Kong, India, Indonesia, Japan, Korea, Malaysia, Pakistan, Philippine, Sri Lanka, Singapore, Thailand and Taiwan. The data uses for the study consists of monthly prices beginning from January 2004 and ends on December 2009. Autocorrelation, run test, unit root test, Ljung- box Q-statistic test and variance ratio were used to test the random walk behavior. The results of the tests show that the monthly return of the Asia-Pacific region stock markets don't follow the random walk behavior and no market is weak-form efficient so investors can predict the prices to earn profits. Omar, Hussain, Bhatti, and Altaf (2013) investigates the weak form efficiency in Karachi stock exchange consists of daily, weekly and monthly returns for the period January 01, 1998 to February 29, 2012 to test random walk behavior. They used unit root tests (ADF and PP tests) and Runs test. The outcome of tests shows that KSE does not follow random walk and there are chances for the technical investors that they can earn the abnormal profit by identifying the trends in KSE. Rehman et al. (2018) research applies multiple unit root tests, Runs Test and State Space Model. The findings provided sufficient evidence that the stock prices of KSE 100 Index, S \& P BSE 500 Index, and CSE All Share Index are not a random walk process and weak form inefficient. 


\subsection{Using as Basis of the Variance Ratio Statistics}

Studies using variance ratio have mixed results. Lima and Tabak (2004) tests the random walk hypothesis for China, Hong Kong and Singapore. They found that Class A shares for Chinese stock exchanges and the Hong Kong equity markets are weak form efficient. However, Singapore and Class B shares for Chinese stock exchanges do not follow the random walk hypothesis. They explained that liquidity and market capitalization may play a role in explaining results of weak form efficiency tests. In the study of Go and Lau (2014), which examines the dynamics of price changes and trading volume of Kuala Lumpur Options and Financial Futures Exchange (KLOFFE) from 2000 to 2008, findings support the Liquidity-Driven Trade hypothesis. In terms of investors' behavior in response to the news, they found that investors are more risk taking in bull market and more risk reverse in bear market. Also, uninformed investors with information asymmetry should expect non-informational trading from informed investors to establish their desired positions for better liquid position. Hoque, Kim, and Pyun (2006) re-examines the random walk hypothesis for eight emerging equity markets in Asia: Hong Kong, Indonesia, Korea, Malaysia, the Philippines, Singapore, Taiwan, and Thailand. The hypothesis is tested with two new variance ratio tests - Wright's rank and sign and Whang-Kim subsampling tests - as well as the conventional Lo-MacKinlay and Chow-Denning tests. They found that (i) the stock prices of the eight Asian countries do not follow random walk with the possible exceptions of Taiwan and Korea, and (ii) the accelerated opening of the eight stock markets to foreign investors following the Asian financial crisis in 1997 has not significantly altered the mean-reversion patterns of stock price vis-à-vis relative market efficiency. Likewise, Kim and Shamsuddin (2008) test for the martingale hypothesis in a group of Asian markets using the new multiple variance ratio tests based on the wild bootstrap and signs. They found that the Hong Kong, Japanese, Korean and Taiwanese markets have been efficient in the weak-form. The markets of Indonesia, Malaysia and Philippines have shown no sign of market efficiency, despite financial liberalization measures implemented since the eighties. Also, the Singaporean and Thai markets have become efficient after the Asian crisis. In the Middle East markets, Smith (2007) investigates five stock markets, Israel, Jordan, Kuwait, Lebanon and Oman, using the multiple variance ratio test. The hypothesis is rejected in two of the markets, those for Kuwaiti domestic companies and Oman. For the Israeli, Jordanian, and Lebanese markets, composite stock price indices follow a random walk or are weak-from efficient.

In general, the above results point toward the notion that the pricing efficiency of a market depends on the level of equity market development as well as the regulatory framework conducive of transparent corporate governance. Camba and Camba (2020) study noted the necessity of supporting policies that continuously promote a welldeveloped financial infrastructure in order to establish depth in financial services and improve stock market liquidity. Furthermore, the findings of Al-Homaidi, Tabash, Al-Ahdal, Farman, and Khan (2019) reveal that leverage, return on assets, and firm age are the essential internal determinants that impact the liquidity of listed firms. Moreover, political stability is also a key factor. Chavali, Alam, and Rosario (2020) examine the influence of elections on the stock market employing market model event study methodology for the sample period 2014 to 2019 . The findings of the study reveal that the impact on the market is not the same between any two elections even when the same party comes to power for the second time. Thus, a semi-strong form of efficient market hypothesis holds true in the context of emerging markets like India.

\section{Research Methodology}

\subsection{Unit Root Tests}

It is a well-known stylized fact that stock prices are nonstationary and are integrated of order 1, (i.e., has a single unit root). The first difference of such series is supposed to be a white noise. The presence of the unit root component can be seen as a white noise series (Rufino, 2013; Wang, Chen, \& Wang, 2018). In this study, we investigated the existence of random walks by employing the Augmented Dickey-Fuller (ADF) (Dickey \& Fuller, 1981) and Phillips-Perron (PP) (Phillips \& Perron, 1988). The general form of ADF and PP tests are as follows (Rehman et al. 2018):

$$
\begin{aligned}
& \Delta \operatorname{SPRICE}_{t}=\alpha+\delta \operatorname{SPRICE_{t-1}}+\sum_{j=1}^{q} \delta_{j} \Delta S P R I C E_{t-1}+\varepsilon_{t} \\
& \triangle S P R I C E_{t}=\alpha+\beta_{t}+\delta S P R I C E_{t-1}+\sum_{j=1}^{q} \delta_{j} \Delta S P R I C E_{t-1}+\varepsilon_{t}
\end{aligned}
$$

$\triangle \operatorname{SPRICE}_{t}=\alpha \operatorname{SPRICE} E_{t-1}+x_{t}^{n} \delta+\varepsilon_{t}$

where $S P R I C E_{t}$ are stock market price, $\varepsilon_{t}$ is white noise and $\alpha=p-1$.

\subsection{Variance Ratio Test}

The variance ratio tests are considered powerful random walk hypothesis test methodologies. Lo and MacKinlay (1988) initiates the conventional variance ratio test. Later, Chow and Denning (1993) modify Lo-MacKinlay's test 
to form a simple multiple variance ratio test. Lo and MacKinlay (1988) proposed the asymptotic distribution of $V R(x ; k)$ by assuming that $k$ is fixed when $T \rightarrow \infty$ (Chang \& Ting, 2000; Lock, 2007; Charles \& Darné, 2009). If $x_{\mathrm{t}}$ is i.i.d., i.e. under the assumption of homoscedasticity, then under the null hypothesis that $V(k)=1$, the test statistic $M_{1}(k)$ is given by

$$
M_{1}(k)=\frac{V R(x ; k)-1}{\varphi(k)^{\frac{1}{2}}}
$$

which follows the standard normal distribution asymptotically. The asymptotic variance, $\varphi(\mathrm{k})$, is given by

$$
\varphi(k)=\frac{2(2 k-1)(k-1)}{3 k T}
$$

To accommodate $x_{\mathrm{t}}$ 's exhibiting conditional heteroscedasticity, Lo and MacKinlay (1988) proposed the heteroscedasticity robust test statistic $M_{2}(k)$

$$
M_{2}(k)=\frac{V R(x ; k)-1}{\ddot{o}^{*}(k)^{1 / 2}}
$$

which follows the standard normal distribution asymptotically under null hypothesis that $V(k)=1$. Chow and Denning (1993) points out that failing to control the test size for variance ratio estimates result in large Type I errors. To control the test size and reduce the Type I errors,
Chow and Denning (1993) extends Lo and MacKinlay's (1988) conventional variance ratio test methodology and form a simple multiple variance ratio test, which uses LoMacKinlay test statistics as the studentized maximum modulus (SMM) statistics (Chen, 2008).

A second approach is available for variance ratio tests of the i.i.d. null. Under this set of assumptions, we may form the joint covariance matrix of the variance ratio test statistics as in Richardson and Smith (1991), and compute the standard Wald statistic for the joint hypothesis that all $m$ variance ratio statistics equal 1. Under the null, the Wald statistic is asymptotic Chi-square with $m$ degrees-of-freedom (Fong, Koh, \& Ouliaris, 1997).

The data of this study consists of the daily closing price of the Philippine stock market, over the period January 2015 to December 2019.

\section{Results and Discussion}

\subsection{Descriptive Statistics}

Figure 1 describes that for the period covered the daily closing stock market price ranges from P6,084.28 to P9,058.62 with mean and median of P7,644.65 and P7,721.02, respectively. Moreover, the Jarque-Bera normality test value of 3.3308 with probability $=0.1891$ suggests the null hypothesis that residuals are normally distributed cannot be rejected.

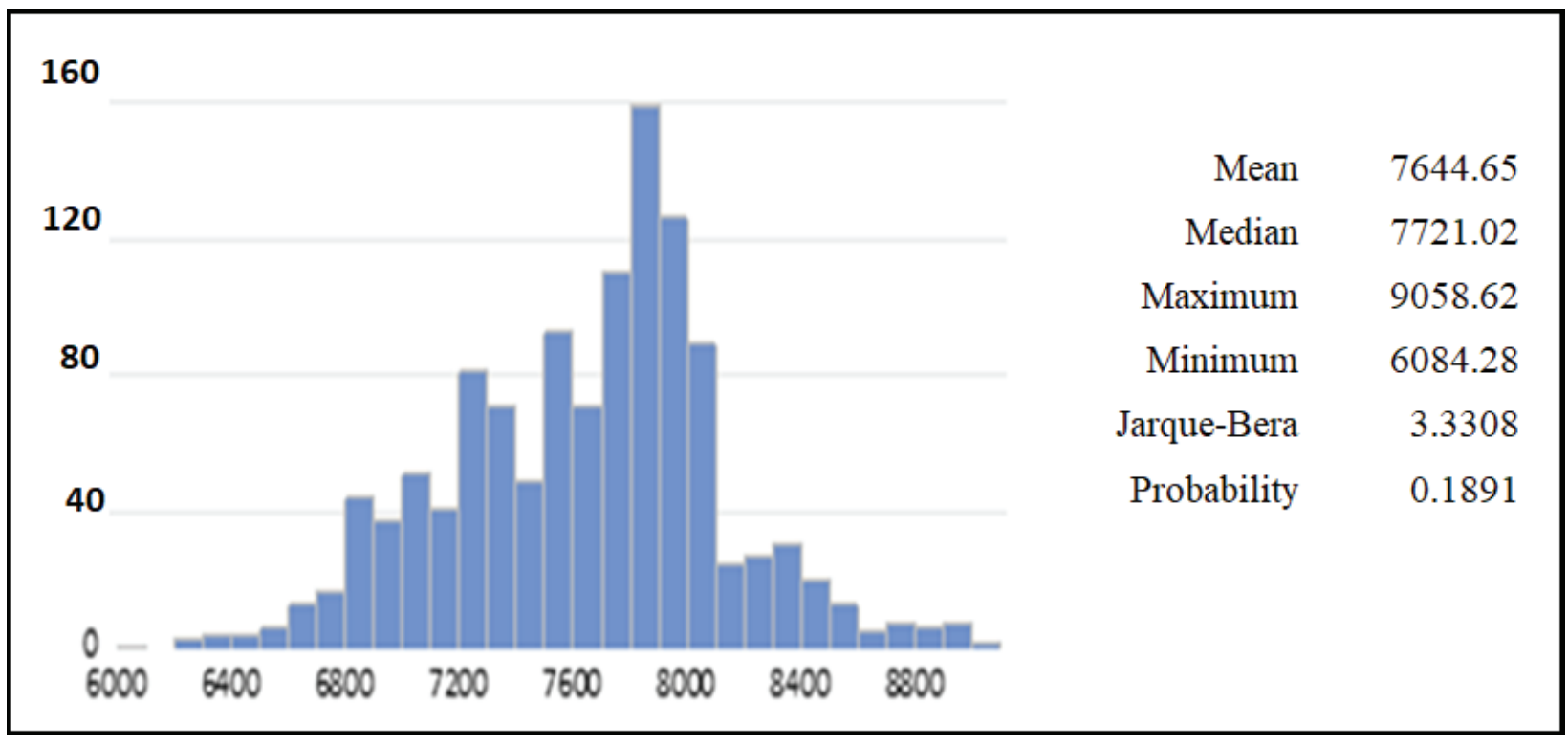

Figure 1: Histogram and Descriptive Statistics 
Table 1: Unit Root Tests

\begin{tabular}{|l|c|c|c|c|c|c|}
\hline \multirow{2}{*}{ Test } & \multicolumn{2}{|c|}{ Level } & \multirow{2}{*}{ Decision } & \multicolumn{2}{|c|}{ First Difference } & \multirow{2}{*}{ Decision } \\
\cline { 2 - 6 } & Intercept & Intercept, Linear Trend & & Intercept & Intercept, Linear Trend & Reject \\
\hline ADF & -2.7346 & -2.9094 & Accept & $-34.8548^{* * *}$ & $-34.8410^{* * *}$ & Reject \\
\hline PP & -2.5493 & -2.7355 & Accept & $-35.1123^{* *}$ & $-35.0968^{* *}$ \\
\hline
\end{tabular}

Note: ADF test was performed using Schwarz information criterion and the automatic lag selection set at 14. PP test was performed with Bartlett Kernel and Newey-West Bandwidth. Statistical significance: ${ }^{* * *}(1 \%),{ }^{* *}(5 \%)$ and ${ }^{*}(10 \%)$.

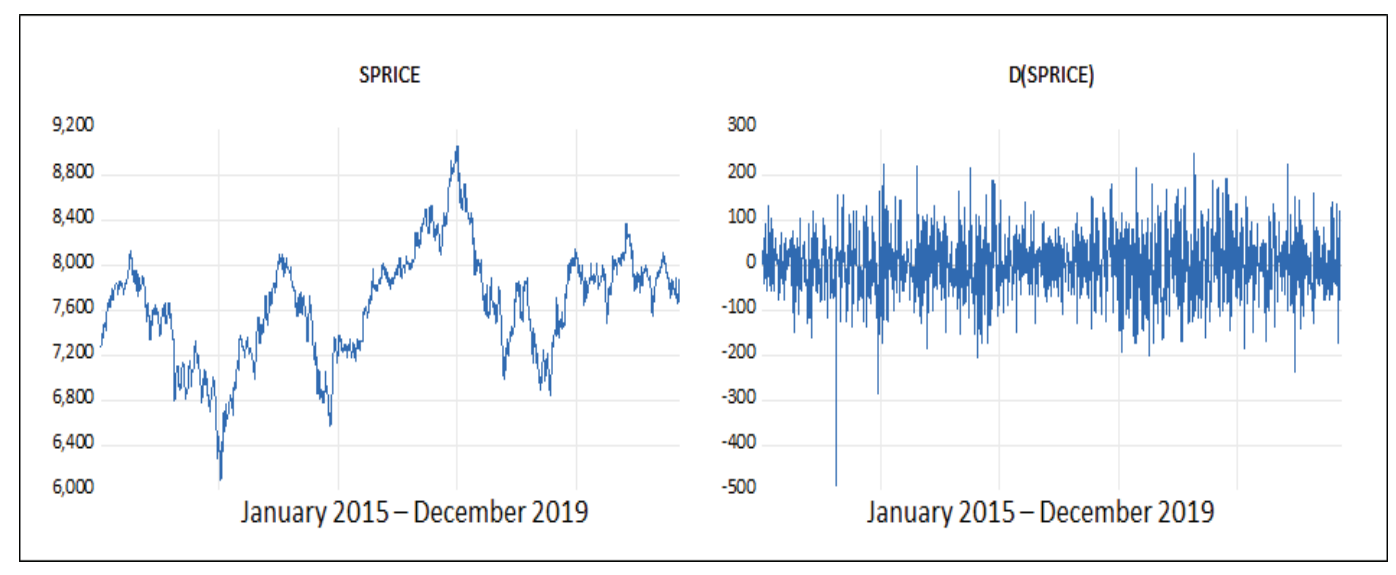

Figure 2: Level and First Difference Plots

\subsection{Unit Root Tests}

Table 1 presents the Augmented Dickey-Fuller (ADF) and Phillips-Perron (PP) unit root tests results of the daily closing stock price in constant and linear trend components. At level the results of the ADF and PP indicates nonstationarity but at the first difference the daily closing price becomes stationary. Thus, with a significance level of 1 percent, one unit root of the time series cannot be rejected while the first difference of the series under consideration is stationary, which confirms that the series is likely to be I(1) and, thus, meets the necessary condition for a random walk. Simply, the daily closing stock price follows a random walk during the January 2015-December 2019 period and the Philippine stock market is an efficient market (i.e., regarded as weak-form efficient). These findings are consistent with the results of Mehmood et al. (2012), Lean and Smyth (2007), and Worthington and Higgs (2006) that there exists a sense of randomness among the stock prices. The explanation of the existence of a random walk in weak-form efficiency can be attributed to market liquidity (Lima \& Tabak, 2004; Go \& Lau, 2014; Camba \& Camba, 2020) because of policies that promote continuous development and modernization of an equity market (Kim \& Shamsuddin, 2008; Rufino, 2013). Figure 2 shows that stock price is non-stationary at level and stationary in its first difference form.

\subsection{Variance Ratio Tests}

Assuming that the daily closing stock market price data follow a random walk, so that variances are computed for differences and assume that the data follow an exponential random walk so that the innovations are obtained by taking $\log$ differences Table 2 presents the variance ratio test results. Here, the Chow-Denning maximum /z/ statistic of 1.7723 and 1.7762 are associated with the period 16 individual test. The approximate $p$-values of 0.2722 and 0.2701 cannot reject the null of a random walk.

The results are quite similar for the Wald test statistic for the joint hypotheses. The individual statistics generally accept the null hypothesis, though the period 16 variance ratio statistic $p$-value of 0.0763 and 0.0757 are significant at $10 \%$ level. Results of the above variance ratio tests consistently fail to reject the random walk hypothesis. That is, empirically establishing the validity of the efficient market hypothesis in the Philippine stock market. Therefore, the daily stock price follows a random walk during the January 2015-December 2019 period and is considered weak-form efficient. Figure 3 displays the graph of the variance ratio statistics and plus or minus two asymptotic standard error bands, along with a horizontal reference line at 1 representing the null hypothesis. 
Table 2: Variance Ratio Test Results

\begin{tabular}{|c|c|c|c|c|}
\hline \multicolumn{5}{|c|}{ Null Hypothesis: SPRICE is a random walk } \\
\hline Joint Tests & \multicolumn{2}{|c|}{ Value } & df & Probability \\
\hline $\operatorname{Max}|z|(\text { at period } 16)^{*}$ & \multicolumn{2}{|c|}{1.7723} & 1216 & 0.2722 \\
\hline Wald (Chi-Square) & \multicolumn{2}{|c|}{4.3131} & 4 & 0.3653 \\
\hline \multicolumn{5}{|c|}{ Individual Tests } \\
\hline Period & Var. Ratio & Std. Error & z-Statistic & Probability \\
\hline 2 & 0.9991 & 0.0287 & -0.0307 & 0.9755 \\
\hline 4 & 0.9440 & 0.0537 & -1.0432 & 0.2969 \\
\hline 8 & 0.8634 & 0.0848 & -1.6108 & 0.1072 \\
\hline 16 & 0.7763 & 0.1262 & -1.7723 & 0.0763 \\
\hline \multicolumn{5}{|c|}{ Null Hypothesis: Log SPRICE is a random walk } \\
\hline Joint Tests & \multicolumn{2}{|c|}{ Value } & df & Probability \\
\hline $\operatorname{Max}|z|(\text { at period } 16)^{*}$ & \multicolumn{2}{|c|}{1.7762} & 1216 & 0.2701 \\
\hline Wald (Chi-Square) & \multicolumn{2}{|c|}{4.6302} & 4 & 0.3274 \\
\hline \multicolumn{5}{|c|}{ Individual Tests } \\
\hline Period & Var. Ratio & Std. Error & z-Statistic & Probability \\
\hline 2 & 1.0061 & 0.0287 & 0.2120 & 0.8321 \\
\hline 4 & 0.9568 & 0.0537 & -0.8054 & 0.4206 \\
\hline 8 & 0.8719 & 0.0848 & -1.5100 & 0.1310 \\
\hline 16 & 0.7758 & 0.1262 & -1.7762 & 0.0757 \\
\hline
\end{tabular}

*Probability approximation using studentized maximum modulus with parameter value 4 and infinite degrees of freedom.

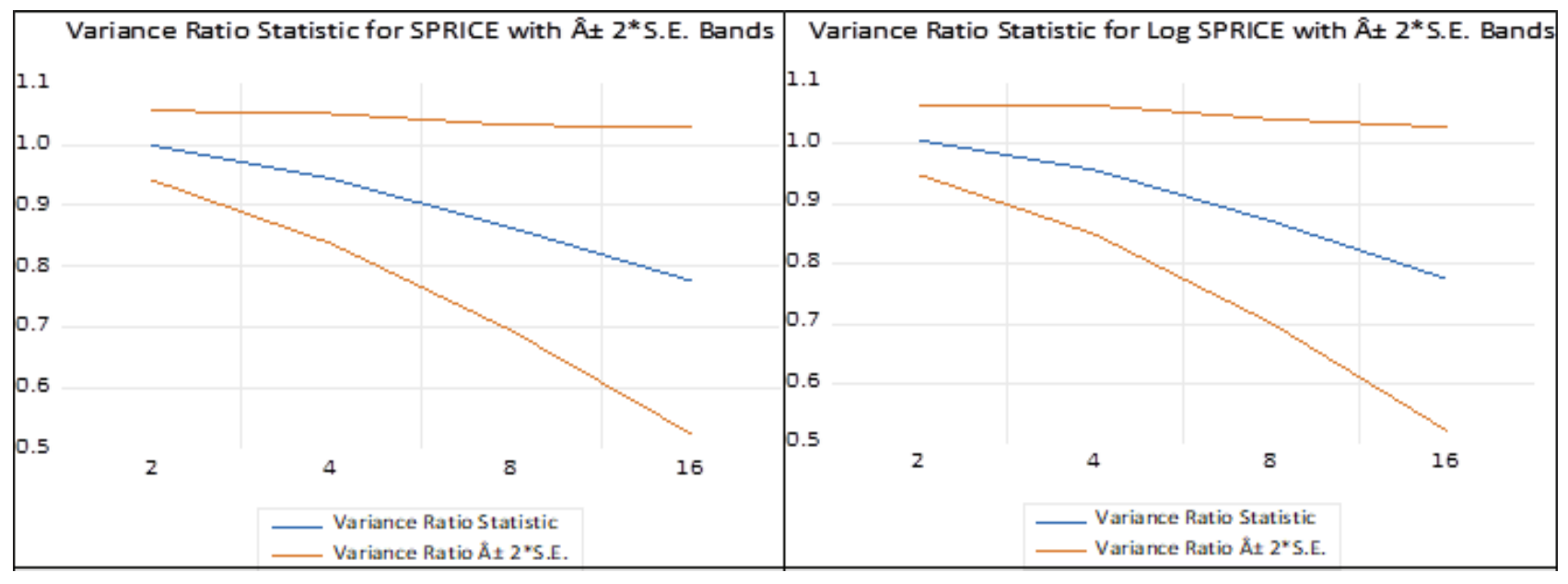

Figure 3: Graph of the Variance Ratio Statistics 


\section{Conclusions}

This research provides evidence of the existence of random walk in the Philippine stock market employing the Augmented Dickey-Fuller (1981) and PhillipsPerron (1988) unit root tests, the Lo-MacKinlay's (1988) conventional variance ratio test and Chow-Denning's (1993) simple multiple variance ratio test. Results of the unit root and variance ratio tests consistently indicate that the null hypothesis of random walk cannot be rejected. Thus, the Philippine stock market is regarded as weakform efficient fully reflecting all information contained in its past prices, which means that studying the behaviors of historical prices cannot earn abnormal returns or profits. Random walk has been held as a sufficient condition for describing the stock market as efficient, which implies that investors cannot predict the market returns or equivalently, abnormal profits cannot be obtained just by knowing the past prices. The implication of weak-form efficiency is the random walk hypothesis, which indicates that successive price changes are random and serially independent.

\section{References}

Al-Homaidi, E., Tabash, M., Al-Ahdal, W., Farman, N., \& Khan, S. (2019). The Liquidity of Indian Firms: Empirical Evidence of 2154 Firms. Journal of Asian Finance, Economics and Business, 7(1), 19-27. https://doi.org/10.13106/jafeb.2020. vol7.no1.19

Brealey, R. A., Myers, S. C., \& Allen, F. (2005). Corporate Finance (8th Ed.). New York, NY: McGraw-Hill Irwin.

Camba, Jr. A. C., \& Camba, A. L. (2020). The Dynamic Relationship of Domestic Credit and Stock Market Liquidity on the Economic Growth of the Philippines. Journal of Asian Finance, Economics and Business, 7(1), 37-46. https://doi:10.13106/ jafeb.2020.vol7.no1.37

Chang, K., \& Ting, K. (2000). A Variance Ratio Test of the Random Walk Hypothesis for Taiwan's Stock Market. Applied Financial Economics, 10, 525-32. https://doi. org/10.1080/096031000416406

Charles, A., \& Darné, O. (2009). Variance ratio tests of random walk: An overview. Journal of Economic Surveys, 23(3), 503527.

Chavali, K., Alam, M., \& Rosario, S. (2020). Stock Market Response to Elections: An Event Study Method. Journal of Asian Finance, Economics and Business, 7(5), 009-018. https:// doi.org/10.13106/jafeb.2020.vo17.no5.009

Chen, J. (2008). Variance Ratio Tests of Random Walk Hypothesis of the Euro Exchange Rate. International Business \& Economics Research Journal, 7(12), 97-106. https://doi.org/10.19030/iber. v7i12.3318
Chow, K. V., \& Denning, K. C. (1993). A Simple Multiple Variance Ratio Test. Journal of Econometrics, 58, 385-401. https://doi. org/10.1016/0304-4076(93)90051-6

Cuthbertson, K., \& Nitzche, D. (2004). Quantitative Financial Economics (2nd Ed.). Chichester, UK: John Wiley and Sons.

Dickey, D. A., \& Fuller, W. A. (1981). Likelihood ratio statistics for autoregressive time series with a unit root. Econometrica, 49(1), 1057-1072.

Dupernex, S. (2007). Why Might Share Prices Follow A Random Walk? Student Economic Review, 21, 167-179.

Fong, W. M., Koh, B., \& Ouliaris, S. (1997). Joint Variance Ratio Tests of the Martingale Hypothesis for Exchange Rates. Journal of Business and Economic Statistics, 1(1), 51-59.

Go, Y., \& Lau, W. (2014). Asymmetric Information Spillovers between Trading Volume and Price Changes in Malaysian Futures Market. Journal of Asian Finance, Economics and Business, 1(3), 5-16. https://doi.org/10.13106/jafeb.2014.vol1. no3.5

Hamid, K., Suleman, T. M., Shah, A. Z. S., \& Akash, I. S. R. (2010). Testing the Weak form of Efficient Market Hypothesis: Empirical Evidence from Asia-Pacific Markets. International Research Journal of Finance and Economics, 58, 121-133. http://dx.doi.org/10.2139/ssrn.2912908

Hoque, H., Kim, J., \& Pyun, C. (2006). A comparison of variance ratio tests of random walk: A case of Asian emerging stock markets. International Review of Economics \& Finance, 16(4), 488-502. https://doi.org/10.1016/j.iref.2006.01.001

Kim, J., \& Shamsuddin, A. (2008). Are Asian stock markets efficient? Evidence from new multiple variance ratio tests. Journal of Empirical Finance, 15, 518-532. https://doi. org/10.1016/j.jempfin.2007.07.001

Kwiatkowski, D., Phillips, P. C. B., Schmidt, P., \& Shin, Y. (1992). Testing the null hypothesis of stationarity against the alternative of a unit root. Journal of Econometrics, 54(1-3), 159-178. https://doi.10.1016/0304-4076(92)90104

Lean, H. H., \& Smyth, R. (2007). Do Asian Stock Markets Follow a Random Walk? Evidence from LM Unit Root Tests with One and Two Structural Breaks. Review of Pacific Basin Financial Markets and Policies, 10(1), 15-31. https://doi.org/10.1142/ S0219091507000933

Lean, H. H., Mishra, V., \& Smyth, R. (2015). The Relevance of Heteroskedasticity and Structural Breaks When Testing for a Random Walk With High-Frequency Financial Data: Evidence from ASEAN Stock Markets. In: Gregorious, G (eds). The Handbook of High Frequency Trading. Singapore: Elsevier. https://doi.org/10.1016/B978-0-12-802205-4.00004-X

Lima, E., \& Tabak, B. (2004). Tests of the random walk hypothesis for equity markets: evidence from China, Hong Kong and Singapore. Applied Economics Letters, 11(4), 255-258. https:// doi.org/10.1080/13504850410001674911

Lo, A. W., \& MacKinlay, A. C. (1988). Stock market prices do not follow random walk: Evidence from a simple specification 
test. The Review of Financial Studies, 1, 41-66. https://doi. org/10.1093/rfs/1.1.41

Lock, D. B. (2007). The Taiwan stock market does follow a random walk. Economics Bulletin, 7(3), 1-8. Retrieved February 11, 2020, from https://core.ac.uk/download/pdf/6310232.pdf

Mehmood, M. S., Mehmood, A., \& Mujtaba, B. G. (2012). Stock Market Prices Follow the Random Walks: Evidence from the Efficiency of Karachi Stock Exchange. European Journal of Economics, Finance and Administrative Sciences, 51, 71-80.

Omar, M. M., Hussain, H., Bhatti, G. A., \& Altaf, M. (2013). Testing of random walks in Karachi stock exchange. Finance Management, 54, 12293-12299.

Phillips, P. C., \& Perron, P. (1988). Testing for a unit root in time series regression. Biometrica, 75(1), 335-346.

Rehman, S., Kashif, M., Chhapra, I. U., \& Rehan, R. (2018). Are Stock Prices a Random Walk? An Empirical Evidence of Asian Stock Market. Etikonomi: Jurnal Ekonomi, 17(2), 237-252. http://dx.doi.org/10.15408/etk.v17i2.7102
Richardson, M., \& Smith, T. (1991). Tests of Financial Models in the Presence of Overlapping Observations. The Review of Financial Studies, 4(2), 227-254.

Rufino, C. (2013). Random walks in the different sub-markets of the Philippine Stock Exchange amid modernization. Philippine Review of Economics, 19(1), 57-82.

Smith, G. (2007). Random walks in Middle Eastern stock markets. Applied Financial Economics, 17(7), 587-596. https://doi. org/10.1080/09603100600911200

Wang, N., Chen, Y. B., \& Wang, B. (2018). Normality of the Stock Index Futures of China. Journal of Mathematical Finance, 8 , 86-101. https://doi.org/10.4236/jmf.2018.81007

Worthington, A. C., \& Higgs, H. (2006). Weak-form market efficiency in Asian emerging and developed equity markets: Comparative tests of random walk behavior. Accounting Research Journal, 19(1), 54-63. 